\title{
Soluble Serum CD81 Is Elevated in Patients with Chronic Hepatitis C and Correlates with Alanine Aminotransferase Serum Activity
}

\author{
Martin-Walter Welker ${ }^{1}$, David Reichert ${ }^{1}$, Simone Susser ${ }^{1}$, Christoph Sarrazin ${ }^{1}$, Yolanda Martinez ${ }^{1}$, Eva \\ Herrmann ${ }^{2}$, Stefan Zeuzem ${ }^{1}$, Albrecht Piiper ${ }^{1}$, Bernd Kronenberger ${ }^{1 *}$
}

1 Medizinische Klinik 1, Klinikum der Johann Wolfgang Goethe-Universität, Theodor-Stern-Kai 7, Frankfurt am Main, Germany, 2 Fachbereich Medizin, Institut für Biostatistik und mathematische Modellierung, Johann Wolfang Goethe-Universität, Frankfurt am Main, Germany

\begin{abstract}
Aim: Cellular CD81 is a well characterized hepatitis C virus (HCV) entry factor, while the relevance of soluble exosomal CD81 in HCV pathogenesis is poorly defined. We performed a case-control study to investigate whether soluble CD81 in the exosomal serum fraction is associated with HCV replication and inflammatory activity.

Patients and Methods: Four cohorts were investigated, patients with chronic hepatitis $C(n=37)$, patients with chronic HCV infection and persistently normal ALT levels $(n=24)$, patients with long term sustained virologic response $(S V R, n=7)$, and healthy volunteers $(n=23)$. Concentration of soluble CD81 was assessed semi-quantitatively after differential centrifugation ranging from $200 \mathrm{~g}$ to $100,000 \mathrm{~g}$ in the fifth centrifugation fraction by immunoblotting and densitometry.

Results: Soluble CD81 was increased in patients with chronic hepatitis $C$ compared to healthy subjects $(p=0.03)$ and cured patients $(p=0.017)$. Patients with chronic HCV infection and persistently normal ALT levels and patients with long term SVR had similar soluble CD81 levels as healthy controls $(p>0.2)$. Overall, soluble CD81 levels were associated with ALT levels $(r=0.334, p=0.016)$ and severe liver fibrosis $(p=0.027)$.

Conclusion: CD81 is increased in the exosomal serum fraction in patients with chronic hepatitis C and appears to be associated with inflammatory activity and severity of fibrosis.
\end{abstract}

Citation: Welker M-W, Reichert D, Susser S, Sarrazin C, Martinez Y, et al. (2012) Soluble Serum CD81 Is Elevated in Patients with Chronic Hepatitis C and Correlates with Alanine Aminotransferase Serum Activity. PLoS ONE 7(2): e30796. doi:10.1371/journal.pone.0030796

Editor: Johan K. Sandberg, Karolinska Institutet, Sweden

Received October 17, 2011; Accepted December 29, 2011; Published February 15, 2012

Copyright: (C) 2012 Welker et al. This is an open-access article distributed under the terms of the Creative Commons Attribution License, which permits unrestricted use, distribution, and reproduction in any medium, provided the original author and source are credited.

Funding: This study was supported by the clinical research unit KFO 129, funded by the German Research Foundation (DFG), and by the Scolari Stiftung. The funders had no role in study design, data collection and analysis, decision to publish, or preparation of the manuscript.

Competing Interests: The authors have declared that no competing interests exist.

* E-mail: Bernd.Kronenberger@kgu.de

\section{Introduction}

Chronic hepatitis $\mathrm{G}$ virus (HCV) infection is a major cause of liver cirrhosis, and hepatocellular carcinoma worldwide $[1,2]$. Recently the protease inhibitors boceprevir and telaprevir, which are associated with considerably enhanced sustained virologic response (SVR) rates in $\mathrm{HCV}$ genotype 1 infected patients in combination with pegylated interferon-alfa and ribavirin, have been approved by the European Medicines Agency and the Food and Drug Administration [3-5]. Nevertheless, approximately one quarter of patients with HCV genotype 1 infection are assumed not to achieve SVR even with triple therapy including either boceprevir or telaprevir [6].

HCV is a plus-strand RNA virus without known ability to integrate its genome into the host genome. Chronic hepatitis $\mathrm{C}$ is characterized by high turnover of infected cells and persistence of HCV requires continuous de novo infection [7-10]. Therefore, inhibition of cell entry is a promising approach in antiviral therapy against HCV. Moreover, cell entry inhibitors may be useful in prevention of otherwise inevitable graft infection after orthotopic liver transplantation in HCV associated liver cirrhosis and hepatocellular carcinoma. Proof-of-concept studies suggest that the new class of HCV entry inhibitors has a substantial capability to widen preventive and therapeutic options in HCV infection [11].

Four essential HCV hepatocyte entry receptors, CD81, the scavenger receptor $\mathrm{B} 1$, claudin-1, and occludin have been identified, yet [12-15]. CD81 is of particular interest because CD81 is not only expressed on hepatocytes but also on peripheral blood mononuclear cells (PBMC). Interaction of HCV with CD81 expressed on PBMC was suggested to be involved in an attenuated innate and adaptive immune response against $\mathrm{HCV}$ as well as in development of extrahepatic HCV manifestations [16-20]. However, these results were challenged by a recent study showing that $\mathrm{HCV}$ envelope 2 proteins have no modulatory effect on natural killer cell functions when expressed as part of cell culture infectious viral particles [21]. The different observations could be explained by differences in the configuration of viral envelope proteins in protein expression systems compared to systems using compete HCV particles [20,21]. 
Yet well known as a cell surface protein, CD81 is also a typical component of exosomes. Exosomes are membrane vesicles secreted by different eukaryotic cells, e.g. hepatocytes and lymphocytes [22-24]. In two studies, exosomes were enriched by differential centrifugation from human plasma from patients with chronic hepatitis G [23,25]. Exosomal CD81 was reliably detectable in the pellet of the fifth fraction of the centrifugation process. Moreover, CD81 exosomes were found to be associated with HCV RNA in plasma obtained from patients chronically infected with HCV [25]. However, neither CD81 levels nor HCV RNA were quantified in enriched plasma or serum, which makes it difficult to assess clinical importance of these findings. Nevertheless, exosomal CD81 may be of relevance in chronic $\mathrm{HCV}$ infection as HCV particles bound to exosomal CD81 could represent an additional $\mathrm{HCV}$ compartment with putative impact on the HCV infection rate or viral persistence, respectively [8].

Aim of the present study was to perform a comprehensive analysis if soluble CD81 is increased in patients with chronic hepatitis $\mathrm{C}$ compared to healthy controls, patients with chronic HCV infection but persistently normal alanine transaminase (ALT) levels, and patients with cured hepatitis C. Therefore, a method to quantify soluble CD81 in the exosomal serum fraction was established, and the association of soluble CD81 in the exosomal serum fraction with clinical and virological parameters within the different cohorts was investigated.

\section{Methods}

\section{Patients}

The present study is a case control study with 23 healthy controls and 37 patients with chronic hepatitis $\mathrm{C}$ and elevated alanine aminotransferase (ALT) level measured at least at 2 time points 14 days or more apart within 6 months before study entry. Furthermore, 24 patients with chronic HCV infection and persistently normal ALT serum levels as documented by three occasional measurements within the last 6 months before study entry and a minimum interval of 4 weeks between measurements, and 7 patients with long-term sustained virologic response 5 years after antiviral therapy with pegylated interferon-alfa $2 \mathrm{a}$ and ribavirin were included. All cohorts were independently recruited. Patients with decompensated liver cirrhosis or co-infection with hepatitis B virus or human immunodeficiency virus were excluded. Diagnosis of chronic HCV infection (>6 months) was confirmed by positive anti-HCV antibodies by third-generation enzyme immunoassay and detectable HCV RNA in serum. Grading and staging of chronic hepatitis $\mathrm{C}$ was done by a local, experienced pathologist according to the histological activity index described by Knodell et al. [26]. Patient cohorts with persistently normal ALT levels and patients with elevated ALT levels were derived from clinical trials performed at the university hospitals Frankfurt/ Main, Germany and Homburg/Saar, Germany. Study protocols were conform to the ethical guidelines of the 1975 Declaration of Helsinki and were approved by the ethic committees of the university hospitals Frankfurt/M, Germany and Homburg/Saar, Germany. Written, informed consent was obtained from every human subject when the samples were collected under the terms of study protocol.

\section{Isolation of CD81 from serum and plasma}

Serum and plasma for ALT and AST levels, CD81 assessment, and HCV-RNA quantification were collected at the same time point and stored at $-80^{\circ} \mathrm{C}$ until use. Enrichment of exosomes was performed according to Masciopinto et al. [25]. In this former study, the CD81 enriched exosomal fraction was identified by immunoblotting in the pellets from the fourth (p4) and - mainly the fifth (p5) centrifugation fraction from plasma [25]. In the current study, differential centrifugation was performed at $200 \mathrm{~g}$

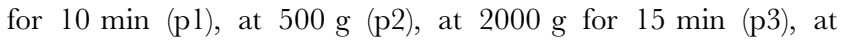
$10,000 \mathrm{~g}$ for $30 \mathrm{~min}(\mathrm{p} 4)$, and finally $100,000 \mathrm{~g}$ for $30 \mathrm{~min}$ (p5). The corresponding pellets (p1, p2, etc.) were each resuspended in $50 \mu \mathrm{l}$ lysis buffer $(100 \mathrm{~mL} 0.5 \mathrm{M}$ TrisHCl pH 7.4, $1.5 \mathrm{mM} \mathrm{NaCl}$, $2.5 \%$ desoxycholic acid, $10 \%$ NP-40, $10 \mathrm{mM}$ ethylenediaminetetraacetic acid, diluted 1:10 in aqua bidest., Merck, Darmstadt, Germany, and Sigma-Aldrich, Taufkirchen, Germany) and stored at $-20^{\circ} \mathrm{C}$ until further analysis. As usage of serum may have some advantages over plasma, e.g. better reflection of biological conditions and easier sample processing, we further optimized detection of CD81 in enriched serum. Therefore, we first compared isolation of not cell-bound CD81 from plasma and serum samples, and then tested different volumes of serum (30 mL, $15 \mathrm{~mL}, 7 \mathrm{~mL}$, and $1 \mathrm{~mL}$ ) to evaluate a possible minimum amount for reliable detection of CD81. In contrast to plasma, serum samples were allowed to clot for $10 \mathrm{~min}$ before centrifugation. After that, serum specimen of the healthy controls and distinct patient groups were processed using the developed optimized serum sample processing protocol.

\section{Immunoblotting of CD81}

Serum derived proteins from different centrifugation steps were separated by dodecylsulfate polyacrylamide gel electrophoresis (SDS-PAGE). As thiol compounds may have a negative impact on anti-CD81 antibody binding [27], a thiol free SDS sample buffer was used. In detail, after dilution of specimens in loading buffer (5 mL glycerin, $2 \mathrm{~mL} 0.625 \mathrm{M}$ TrisHCl, $\mathrm{pH}$ 6,8, $0.2 \mathrm{~g}$ SDS, $0.1 \mathrm{~mL}$ bromphenoleblue as $1 \%$ ethanol dilution, $2.4 \mathrm{~mL}$ aqua bidest.), the samples were separated by SDS-page (50 mA, $90 \mathrm{~min}$ ) and electrophoretic transferred (110 mA, $90 \mathrm{~min})$ to nitrocellulose membranes Whatman Schleicher \& Schell, Dassel, Germany). Nonspecific binding sites were blocked by incubation in 5\% skim milk in buffer TBST (150 mM NaCl; $30 \mathrm{mM}$ Tris, pH 7.4; 0.05\% Tween20) for 12 hours at $+4^{\circ} \mathrm{C}$. Primary anti-CD81 antibody (mouse-anti-human antibody, clone JS-81, Pharmingen, Heidelberg, Germany) were allowed to bind for a minimum of 2 hours. Detection of CD81/antibody immune complexes was performed using horse radish peroxidase-conjugated antibodies (Bio-Rad Laboratories, Hercules CA, U.S.A.) and enhanced chemiluminescence (Millipore GmbH, Schwalbach, Germany). By staining with monoclonal anti-CD81 antibodies and consecutive polyclonal horse raddish peroxidase-conjugated antibodies or staining with polyclonal horse raddish peroxidase-conjugated antibodies only, specific detection of CD81 was confirmed (data not shown). Further semi-quantitative analysis was performed by automated densitometry.

\section{Quantification of CD81}

Huh7 cells are characterized by high CD81 expression [28]. Serial dilutions of a cell lysate of $10^{4} \mathrm{Huh} 7$ were used as standard for semi-quantitative assessment of serum CD81. Aliquots of the lysate were stored at $-80^{\circ} \mathrm{C}$ until use, and applied as the same standard for all experiments. CD81 in Huh7 cell lysates was detected by immunoblotting and densitometric analysis by use of an analysis program (Gelscan 5, BioSciTec GmbH, Frankfurt, Germany). Concentration of serum derived CD81 was assessed semi-quantitatively in relation to the standard curve obtained from the Huh7 cell lysate dilutions by densitometry and expressed as relative units (RU). 


\section{Measurement of HCV RNA from native serum and HCV genotyping}

Quantitative assessment of HCV RNA in serum was performed by a quantitative reverse transcription polymerase chain reaction assay (Cobas Amplicor HCV MonitorTM 2.0, Roche Diagnostic Systems, Branchburg, NJ; lower detection limit, $600 \mathrm{IU} / \mathrm{mL}$ ). Samples with HCV RNA concentration above the upper detection limit above $800.000 \mathrm{IU} / \mathrm{mL}$ were diluted appropriately. HCV genotyping was performed by reverse hybridization assay (Inno LiPA HCV II, Innogenetics, Gent, Belgium). All contamination prevention measures suggested by Kwok and Higuchi were strictly applied [29].

\section{Measurement of HCV RNA in enriched serum}

For comparison with serum HCV RNA and correlation to CD81 concentration within enriched serum fraction p5, HCV RNA was assessed in enriched serum, also. Therefore, differential centrifugation was performed in accordance to the CD81 enrichment protocol. Each pellet from a given centrifugation step was resuspended in $0.25 \mathrm{~mL}$ PBS, and HCV RNA was extracted fully automatic (COBAS-Ampliprep, Roche, Mannheim, Germany). Quantification of HCV RNA was performed standardized by real-time polymerase chain reaction (COBAS-Taqman 48 Analyzer Roche, Mannheim, Germany).

\section{Statistical analyses}

Unless indicated otherwise, all tests were two tailed and $p$ values $<0.05$ were considered significant. Clinical and biochemical characteristics of patients were expressed as mean \pm standard deviation (SD) or median and range as appropriate. Correlations between two variables were calculated by the spearman test. Furthermore, Kruskal-Wallis test, Friedman test, Wilcoxon-paired sample test and Wilcoxon Mann-Whitney $\mathrm{U}$ test were applied as appropriate. A Bonferroni correction was applied, if multiple comparisons were performed. A receiver operating characteristic analysis was performed to compare CD81-p5 and severity of liver fibrosis.

\section{Results}

\section{Detection of CD81 in the exosomal serum fraction}

Detection of exosomal CD81 in plasma from patients with chronic hepatitis $\mathrm{C}$ has been previously described by Masciopinto et al. [25]. In the present study, we investigated whether exosomal CD81 is also detectable in human serum. For this purpose, differential centrifugation for enrichment of exosomal CD81 was performed with human plasma and serum as previously described for plasma, followed by immunoblotting with CD81 specific monoclonal antibodies [25]. Lysates from Huh7 cells characterized by high CD81 expression were used as positive control. Consistently, CD81 was absent in fractions p2 and p3, weakly detectable in fraction $\mathrm{p} 4$ and reliably detectable in the exosomal fraction p5 of both plasma and serum samples (Figure 1 A, B). The only difference in detection of CD81 in serum vs. plasma samples was found in the $\mathrm{pl}$ fraction corresponding to the cellular fraction. Here, CD81 was detectable in plasma samples only. Fraction p5 containing exosomal CD81 was used for subsequent analyses. Enrichment of CD81 from different volumes of serum ranging from $1 \mathrm{~mL}$ to $30 \mathrm{~mL}$ showed that robust detection of CD81 was feasible with the smallest tested volume of $1 \mathrm{~mL}$ serum. This volume was used in all further analyses.

\section{Quantification of serum CD81}

We next investigated whether CD81 concentration in the p5 fraction can be quantified. For this purpose, different dilutions of Huh7cell lysates were detected by Western blot analysis and quantified by densitometry. As shown in Figure $1 \mathrm{C}$ and D, this approach allowed semiquantitative assessment of CD81 in the p5 fraction (CD81-p5). In the subsequent experiments, different dilutions of Huh7 lysates covering the range of serum CD81-p5 were used as reference standard. Stock solutions from the same lysate were used for all analyses (Figure 2A).

\section{Association of serum CD81-p5 with chronic hepatitis C virus infection}

Aim of this study was to investigate whether soluble CD81 levels are increased in patients with chronic hepatitis C. Therefore, the concentration of soluble CD81 in the exosomal fraction p5 was compared between a cohort of 23 healthy controls and 37 patients with chronic hepatitis C. As shown in Figure 2, the serum CD81 concentration in fraction p5 was significantly higher in patients with chronic hepatitis $\mathrm{C}$ compared with healthy controls (Figure 2 A, B). In patients with chronic hepatitis C, CD81-p5 was neither associated with patients characteristics such as age and gender (Table 1). Apparently, there was no association between CD81-p5 and HCV genotype, however, reliable conclusions on the association between HCV genotype and soluble CD81 cannot be drawn due to imbalanced genotype distribution in the different cohorts. To investigate whether HCV infection is associated with an increase of serum obtained CD81, CD81-p5 was analyzed in a cohort of patients with long term cure of HCV after pegylated interferon-alfa based antiviral therapy and compared with CD81p5 in healthy controls and in patients with chronic hepatitis C. In patients with cured hepatitis $\mathrm{C}$ the CD81-p5 level was similar to healthy controls and significantly lower than in patients with chronic hepatitis C (Figure 2 B).

\section{CD81-p5 concentration and inflammatory activity}

Exosomal CD81 may also be associated with inflammatory activity. To investigate a potential association between the CD81 concentration in the p5 fraction and liver inflammation, CD81-p5 was analyzed in a cohort of patients with chronic hepatitis $\mathrm{C}$ and persistently normal ALT levels. In the present study, patients with chronic hepatitis $\mathrm{C}$ and persistently normal ALT levels showed lower CD81-p5 levels than patients with chronic hepatitis $\mathrm{C}$ and elevated ALT levels and comparable levels of CD81-p5 with healthy controls and patients with cured HCV.

Overall, the CD81-p5 level was associated with serum ALT activity in patients with chronic hepatitis $\mathrm{C}$ with or without ALT elevation $(r=0.372, p=0.003$, Figure 2G). Furthermore, we observed a significant association between CD81-p5 and aspartate aminotransferase serum levels $(r=0.306, p=0.017$; Figure 2D). Both associations were significant for the complete cohort of patient with chronic HCV infection only, but not for subgroups with normal or elevated ALT levels, respectively ( $p>0.2$ for both). Gamma-glutamyl transferase levels were significantly associated with ALT and AST serum levels but not with CD81-p5 ( $\mathrm{r}=0.589$; $\mathrm{p}<0.001 ; \mathrm{r}=0.576, \mathrm{p}<0.001 ; \mathrm{r}=0.228, \mathrm{p}=0.08$, respectively).

We also analyzed the association between CD81-p5 and histological liver damage. CD81-p5 was significantly associated with severe vs. non severe fibrosis (area under curve 0.699, $p=0.027$, Figure 3). However, no correlation was noticed between CD81-p5 and histological necroinflammatory activity $(\mathrm{p}>0.2)$. 
$\mathbf{A}$

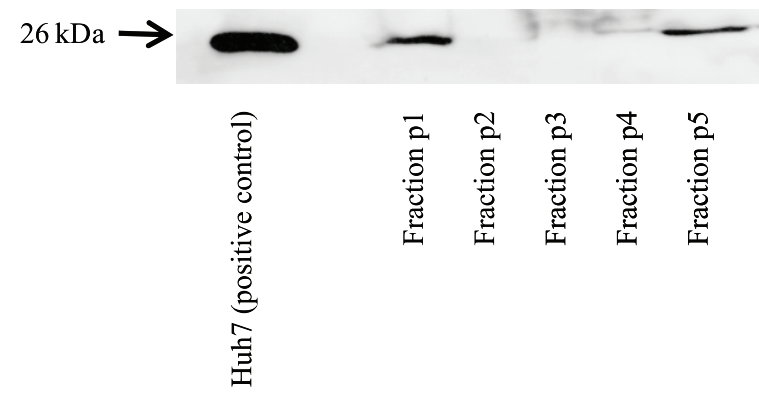

C $26 \mathrm{kDa} \rightarrow-m-\infty=0$
B

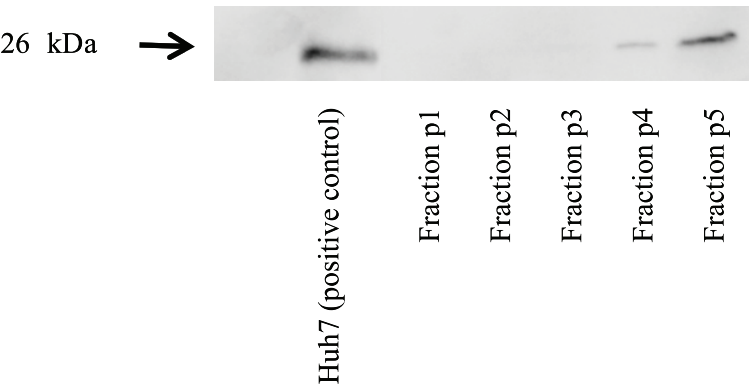

D Standard curve

$\mathrm{y}=37686 \mathrm{x}+364134$

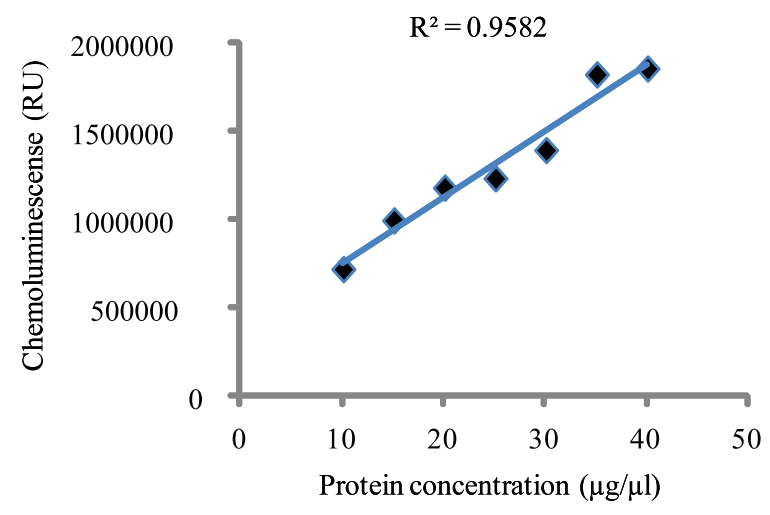

Figure 1. Enrichment and quantification of soluble CD81. (A, B) Immunoblotting of soluble CD81 is shown after enrichment by differential centrifugation of frozen (A) plasma and (B) serum samples. Huh7 cells served as positive control, and HepG2 cells as negative control. While only a marginal fraction was detectable in fraction $\mathrm{p} 4$, the main portion was detectable in fraction $\mathrm{p} 5$, comparable between plasma and serum samples. (C, D). Soluble CD81 concentration was assessed semi-quantitatively by use of dilutions from a Huh7 cell lysate by densitometric analysis. The lysate dilution immunoblot analysis and the corresponding obtained standard curve are shown in (C) and (D), respectively.

doi:10.1371/journal.pone.0030796.g001

Serum ALT and AST levels also did not show significant correlations with necroinflammatory activity ( $\mathrm{p}>0.2$ for both).

\section{CD81-p5 and HCV RNA}

As HCV binds to CD81, the CD81 concentration in fraction p5 may be associated with the HCV RNA level. The HCV RNA concentration was quantified in unfractionated serum and in the enriched serum fraction $\mathrm{p} 5$ in all patients with chronic $\mathrm{HCV}$ infection (Figure $4 \mathrm{~A}, \mathrm{~B}$ ). The HCV RNA concentration in unfractionated serum was significantly correlated with the HCV RNA concentration in fraction $\mathrm{p} 5(\mathrm{p}<0.001 ; \mathrm{r}=0.696$, Figure $4 \mathrm{C})$. However, the CD81 concentration in fraction p5 neither correlated with the HCV RNA concentration in unfractionated serum $(p=0.373 ; r=0.135$, Figure 4A) nor with the HCV RNA concentration in fraction $\mathrm{p} 5(\mathrm{p}=0.39 ; \mathrm{r}=0.15$, Figure $4 \mathrm{D})$. Accordant analyses of the subgroups of patients with persistently normal or elevated ALT serum levels showed no correlation between HCV RNA concentration in serum or HCV RNA concentration in fraction p5 with CD81-p5, respectively ( $>0.2$ for both subgroups).

\section{Discussion}

The tetraspanin CD81 is an essential HCV hepatocyte cell entry receptor $[13,14]$. Interplay between $\mathrm{HCV}$ and CD81 expressed on PBMC has been related to $\mathrm{HCV}$ persistence as well as modulation of extrahepatic manifestations of chronic $\mathrm{HCV}$ infection [16-20,27].

CD81 containing exosomes have not been studied in larger cohorts of patients with chronic hepatitis C, so far. Exosomes are small vesicles secreted by vital cells only, amongst others considered to modify immune response in viral and malignant diseases [23,30-33]. For instance, exosome mediated infection of cells has been described in human immunodeficiency virus infection [32]. Moreover, exosome mediated intercellular transfer of CD81 and enhancement of CD81 concentration on cell surfaces by mergence has been observed [23]. Therefore, exosomal CD81 taken up by target cells, e.g. hepatocytes, could increase HCV receptor density and facilitate $\mathrm{HCV}$ entry, and HCV particles bound to exosomal CD81 could moreover represent an additional $\mathrm{HCV}$ compartment with putative relevance for the HCV infection rate. Aim of the present study was to quantify and compare CD81 in the exosomal serum fraction in patients with chronic hepatitis $\mathrm{C}$ compared to healthy controls and patients with cured hepatitis, and furthermore to investigate whether soluble CD81 in the exosomal serum fraction is associated with inflammatory activity in chronic hepatitis C.

Enrichment of exosomes from plasma or serum, as performed within the current study, can be performed by differential centrifugation [23,25]. Here, CD81 is an exosomal marker 


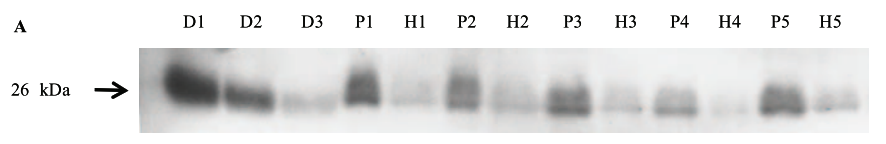

B

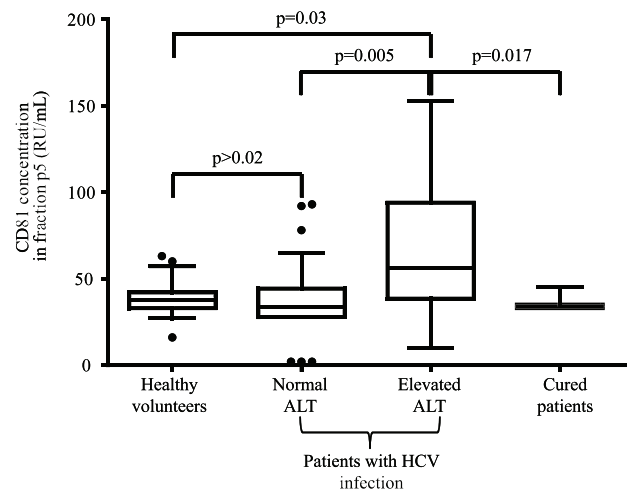

$\mathrm{C}$

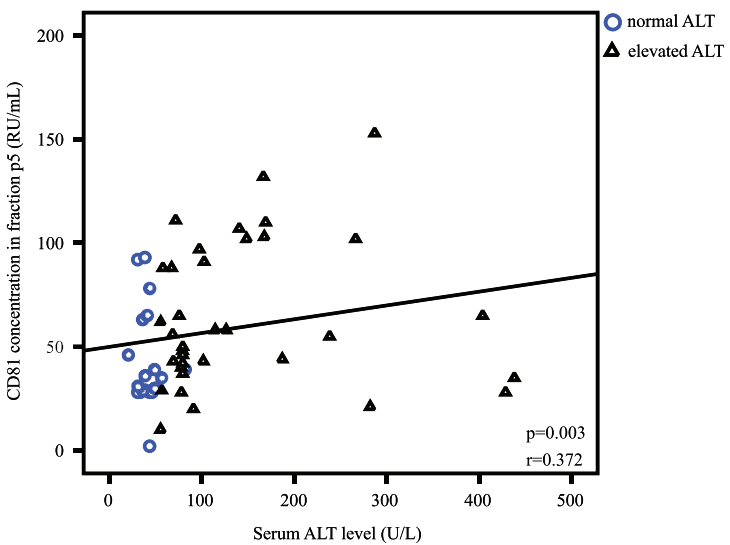

D

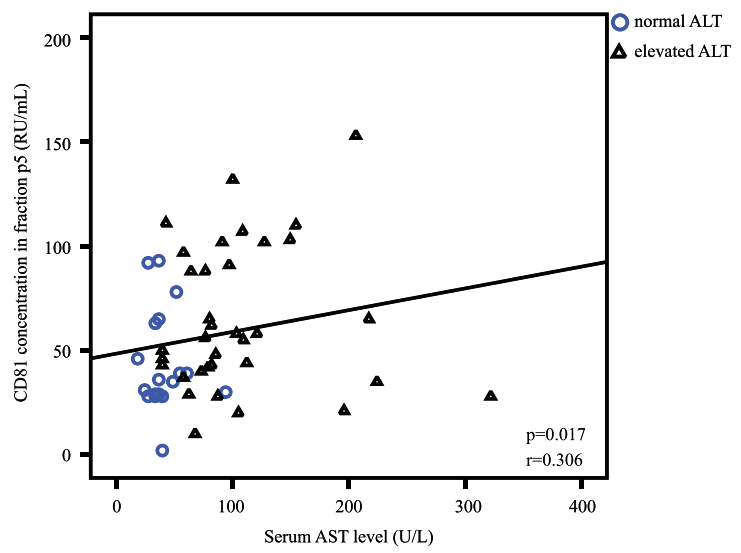

Figure 2. Quantification of soluble CD81 serum levels in different populations and correlation to serum ALT and AST levels. (A) Immunoblot analysis from representative patient samples (P1-P5) and healthy controls (H1-H5) as well as Huh7 dilution series (D1-D3). Enrichment of soluble CD81 had been standardized before sample processing, and a standardized volume of $1 \mathrm{~mL}$ serum was used for CD81 enrichment and quantification in all study samples analyzed. (B) Enriched CD81 serum concentrations given in healthy volunteers $(n=23)$, patients with chronic HCV infection and persistently normal ALT levels $(n=24)$, patients with chronic hepatitis C and elevated ALT levels $(n=37)$, and patients with long-term SVR $(n=7)$. The CD81 concentration is given in relative units $(R U) / m L$ as box-and-whisker plot showing median, 25 and 75 quartiles as well as the total range. Differences between two groups were calculated by the Mann-Whitney $\mathrm{U}$ test. (C) Correlation of CD81 concentration in fraction p5 given in $\mathrm{RU} / \mathrm{mL}$ and serum ALT level given in $\mathrm{U} / \mathrm{mL}$ in all patients with chronic $\mathrm{HCV}$ infection, including patients with elevated $(\triangle)$ and persistently normal $(\bigcirc)$ ALT levels $(n=61)$. Correlations between two variables were assessed by the Spearman's rank correlation test. (D) Correlation of CD81 concentration in fraction p5 given in RU/mL and serum AST level given in $\mathrm{U} / \mathrm{mL}$ in all patients with chronic HCV infection, including patients with elevated $(\triangle)$ and persistently normal $(\bigcirc)$ ALT levels $(n=61)$. Correlations between two variables were assessed by the Spearman's rank correlation test. doi:10.1371/journal.pone.0030796.g002

protein, and the CD81 content in the exosomal fraction can be considered to be mainly of exosomal origin [23,25]. Therefore, we measured the concentration of soluble CD81 after differential centrifugation of a standardized volume of $1 \mathrm{~mL}$ serum.

In the present study, soluble CD81 levels were increased in the exosomal serum fraction $\mathrm{p} 5$ in patients with chronic hepatitis $\mathrm{C}$ compared to healthy volunteers. Moreover, in patients cured from hepatitis C, CD81 levels normalized to levels found in healthy subjects. Overall these results suggest that infection with the hepatitis $\mathrm{C}$ virus is associated with increase of soluble CD81.

Soluble CD81 could be associated with HCV replication. Therefore, we assessed whether soluble CD81 correlates with the HCV RNA level. In the present study, however, HCV RNA serum levels were not correlated with the GD81 concentration in the exosomal serum fraction p5. HCV RNA may also bind to exosomal CD81 which is suggested by data from Masciopinto et al., who have shown an association of HCV envelope proteins and HCV RNA with exosomal CD81 in vitro [25]. In the present study, HCV RNA was enriched in the exosomal serum fraction; however, the concentration of HCV RNA in the exosomal serum fraction was not correlated with the soluble CD81 concentration. Therefore, it may be concluded that exosomal CD81 is not directly involved in HCV replication.

Recently, proinflammatory exosomes have been described to contribute to inflammation e.g. in sarcoidosis [34]. To investigate whether increased soluble CD81 levels are associated with disease activity in chronic HCV infection, we compared soluble CD81 serum levels in patients with chronic hepatitis $\mathrm{C}$ to a cohort of patients with HCV infection but persistently normal ALT levels as ALT is a surrogate marker for apoptosis and necroinflammation in chronic hepatitis C. It is estimated that approximately $30 \%$ of patients with HCV show normal ALT levels [35]. The reason therefore is unknown, but it was suggested that an arbitrary high upper limit of normal range may contribute to this phenomenon [36]. The long term clinical outcome is not completely known.

Patients with HCV infection and persistently normal ALT levels may show a more benign course than patients with elevated ALT levels. Nevertheless, several studies described significant histological liver lesions and increased ALT levels over time in these patients [36-40], indicating that this specific cohort may develop 
Table 1. Baseline characteristics of patients and healthy controls.

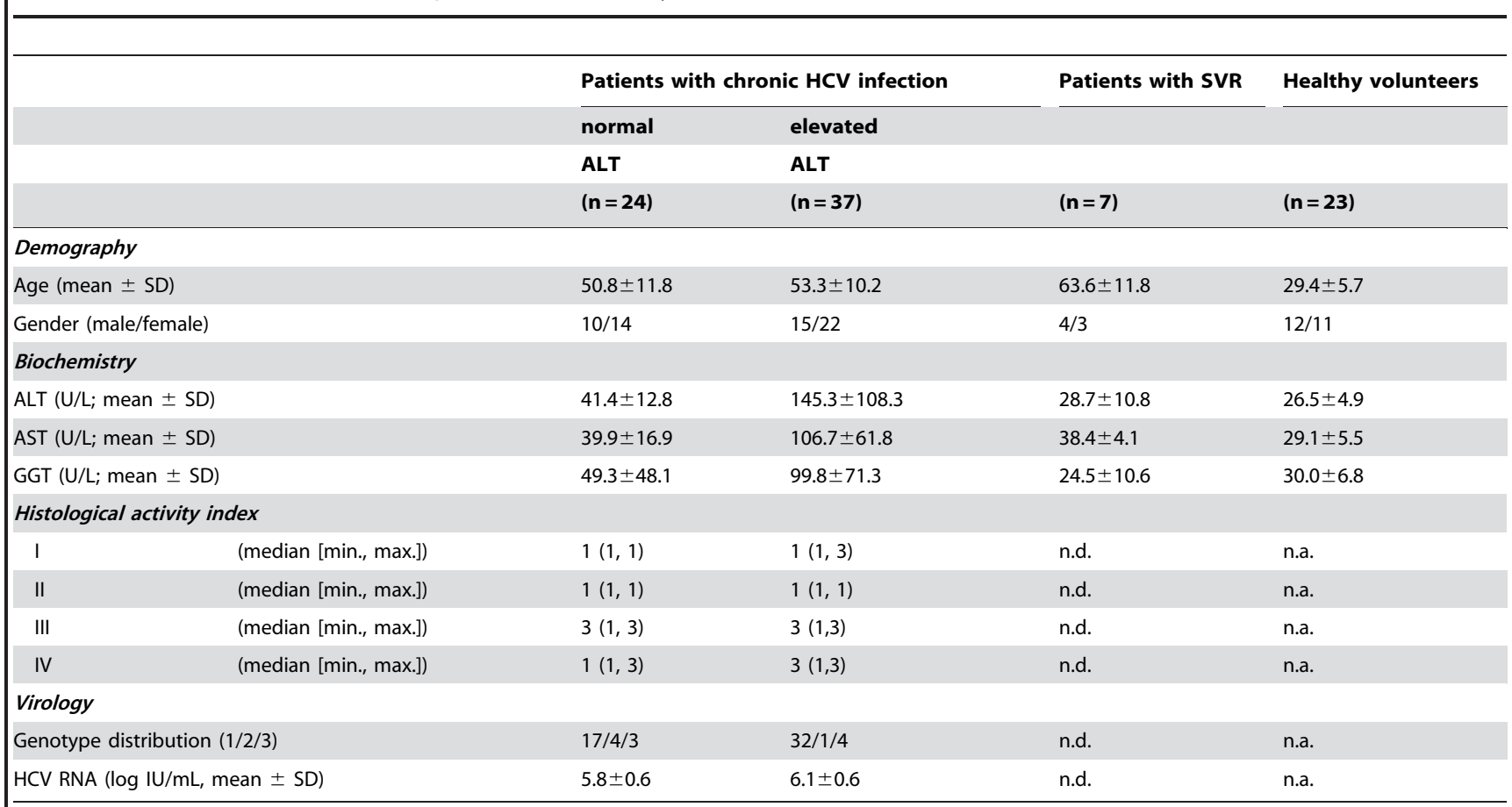

ALT, alanine transaminase; AST, aspartate transaminase; GGT, gamma-glutamyl transferase (the upper limit of normal was $50 \mathrm{U} / \mathrm{L}, 50 \mathrm{U} / \mathrm{L}, 39 \mathrm{U} / \mathrm{L}$ for $\mathrm{ALT}$, AST and GGT); max., maximum; min; minimum; n.a., not applicable; n.d., not done NR, nonresponse SD, standard deviation; SVR, sustained virologic response.

doi:10.1371/journal.pone.0030796.t001

liver damage in the absence of surrogate cell death markers. In the current study, soluble CD81 levels were significantly higher in patients with hepatitis $\mathrm{C}$ compared to patients with HCV infection and normal ALT levels. This may indicate that increase of soluble

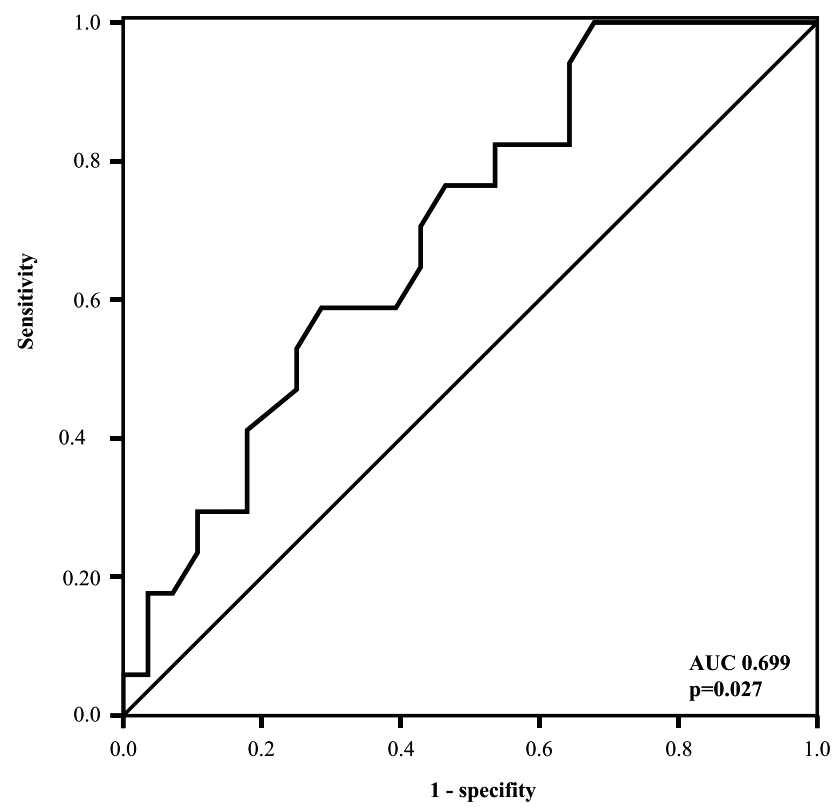

Figure 3. Receiver operating characteristic showing the association between soluble CD81 serum concentration and fibrosis. Higher CD81-p5 levels were associated with sever fibroses (area under curve, AUC, 0.699; $p=0.027$ ).

doi:10.1371/journal.pone.0030796.g003
CD81 in patients with chronic hepatitis $\mathrm{C}$ is mostly related with HCV associated necroinflammation.

To further investigate the observed correlation between soluble CD81 levels and necroinflammatory activity, we compared CD81 levels to ALT and AST levels. Here, a significant correlation between serum ALT as well as AST levels and soluble CD81 was observed. This may indicate an association between hepatocyte cell death and higher CD81 serum levels. The association between soluble CD81 and surrogate markers of cell death could be due to release of CD81 containing exosomes or cell detritus from hepatocytes during the necroinflammatory process. However, the correlation coefficients between soluble CD81 levels and biochemical markers of liver damage, even though statistically significant, were weak. A final conclusion that soluble CD81 levels are mostly derived from inflammatory processes in patients with hepatitis $\mathrm{C}$ cannot be drawn from the results of the current study.

Another explanation for the increase of soluble CD81 levels in patients with chronic hepatitis $\mathrm{C}$ is secretion of CD81 containing exosomes by lymphocytes. Interaction of $\mathrm{HCV}$ particles with CD81 expressed on PBMC as well as alteration of CD81 expression on PBMC during HCV infection is well known and of clinical importance [18,19,41]. Potential interaction of PBMC released CD81 exosomes with $\mathrm{HCV}$ particles may occur and influence hepatic inflammation in chronic hepatitis C. Here, further studies defining the source of soluble CD81 in HCV infection are necessary.

In summary, the results of the present study show that chronic HCV infection is associated with increase of soluble CD81 in the exosomal serum fraction. CD81 in the exosomal fraction in patients with chronic hepatitis $\mathrm{C}$ appears to be associated with inflammatory activity. This is a new finding with potential implications in the understanding of $\mathrm{HCV}$ persistence and $\mathrm{HCV}$-associated necroinflammation. In concordance, soluble CD81 levels were associated with higher stage liver fibrosis. 
$\mathbf{A}$

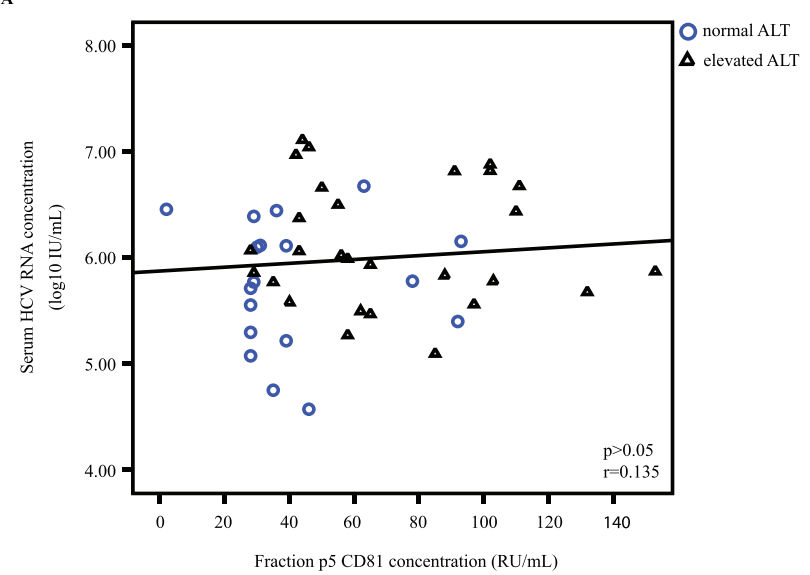

B

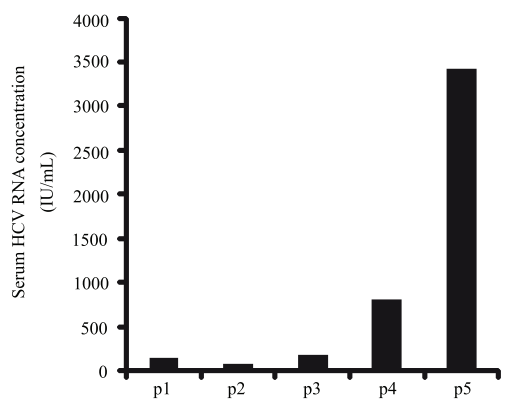

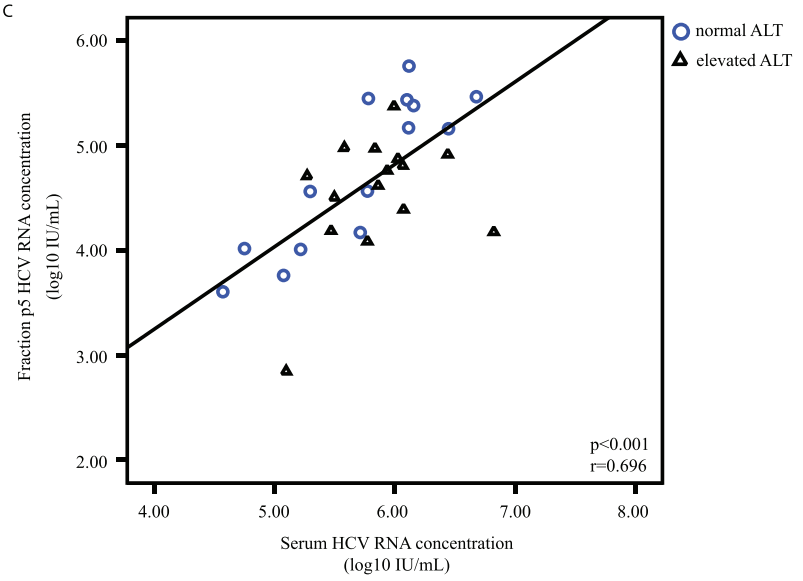

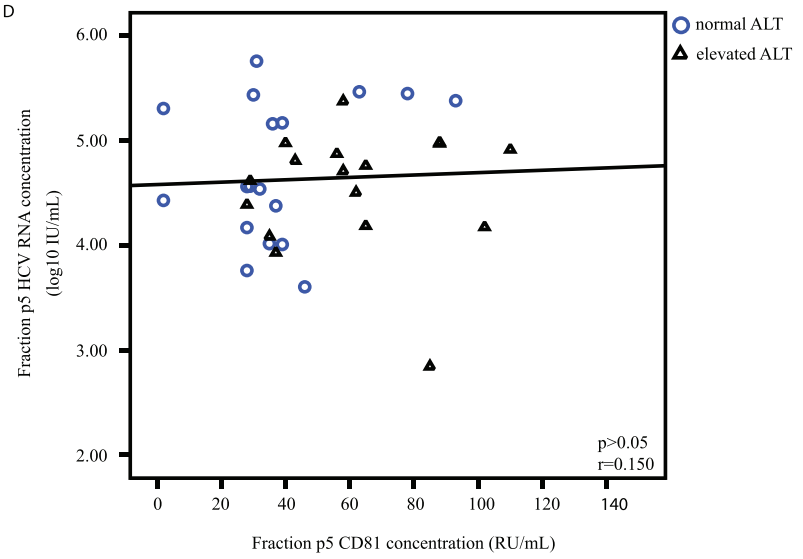

Figure 4. Association of HCV RNA levels and the concentration of CD81 in serum fraction p5 in patients with chronic hepatitis C and persistently normal $(O)$ and elevated $(\triangle)$ ALT levels. Correlations between two variables were assessed by the Spearman's rank correlation test. (A) Serum HCV RNA and CD81 concentration in fraction $\mathrm{p} 5$ were not correlated. (B) Quantification of HCV RNA in the different serum fractions showing the highest HCV RNA concentration in fraction p5. (C) Correlation between HCV RNA concentration in fraction p5 and serum showing high correlation between HCV RNA concentration in unfractionated and enriched serum. (D) Concentrations of HCV RNA in fraction p5 and CD81 fraction $\mathrm{p} 5$ showed no correlation. $\mathrm{P}$ values and correlation coefficient $\mathrm{r}$ are given for each correlation.

doi:10.1371/journal.pone.0030796.g004

\section{Author Contributions}

Conceived and designed the experiments: MWW CS EH SZ AP BK. Performed the experiments: DR SS YM. Analyzed the data: MWW DR

\section{References}

1. Alter MJ, Margolis HS, Krawczynski K, Judson FN, Mares A, et al. (1992) The natural history of community-acquired hepatitis $\mathrm{C}$ in the United States. The Sentinel Counties Chronic non-A, non-B Hepatitis Study Team. N Engl J Med 327: 1899-1905.

2. Saito I, Miyamura T, Ohbayashi A, Harada H, Katayama T, et al. (1990) Hepatitis C virus infection is associated with the development of hepatocellular carcinoma. Proc Natl Acad Sci U S A 87: 6547-6549.

3. Lange CM, Sarrazin C, Zeuzem S (2010) Review article: specifically targeted anti-viral therapy for hepatitis C - a new era in therapy. Aliment Pharmacol Ther 32: 14-28.

4. Jacobson IM, McHutchison JG, Dusheiko G, Di Bisceglie AM, Reddy KR, et al. (2011) Telaprevir for Previously Untreated Chronic Hepatitis C Virus Infection. New England Journal of Medicine 364: 2405-2416.

5. Poordad F, McCone J, Bacon BR, Bruno S, Manns MP, et al. (2011) Boceprevir for Untreated Chronic HCV Genotype 1 Infection. New England Journal of Medicine 364: 1195-1206.

6. Kronenberger B, Zeuzem S (2009) Current and future treatment options for HCV. Annals of Hepatology 8: 103-112.

7. Wakita T, Pietschmann T, Kato T, Date T, Miyamoto M, et al. (2005) Production of infectious hepatitis $\mathrm{C}$ virus in tissue culture from a cloned viral genome. Nat Med 11: 791-796.
CS EH SZ AP BK. Contributed reagents/materials/analysis tools: CS EH SZ AP BK. Wrote the paper: MWW CS SZ AP BK.

8. Welker MW, Zeuzem S (2009) Occult Hepatitis C: How Convincing Are the Current Data? Hepatology 49: 665-675.

9. Moradpour D, Penin F, Rice CM (2007) Replication of hepatitis C virus. Nat Rev Microbiol 5: 453-463.

10. Perelson AS, Herrmann E, Micol F, Zeuzem S (2005) New kinetic models for the hepatitis C virus. Hepatology 42: 749-754.

11. Zeisel MB, Fofana I, Fafi-Kremer S, Baumert TF (2011) Hepatitis C virus entry into hepatocytes: Molecular mechanisms and targets for antiviral therapies. Journal of Hepatology 54: 566-576.

12. Ploss A, Evans MJ, Gaysinskaya VA, Panis M, You H, et al. (2009) Human occludin is a hepatitis $\mathrm{C}$ virus entry factor required for infection of mouse cells. Nature 457: 882-886.

13. Pileri P, Uematsu Y, Campagnoli S, Galli G, Falugi F, et al. (1998) Binding of hepatitis $\mathrm{C}$ virus to CD81. Science 282: 938-941.

14. Bartosch B, Vitelli A, Granier C, Goujon G, Dubuisson J, et al. (2003) Cell entry of hepatitis $\mathrm{C}$ virus requires a set of co-receptors that include the CD81 tetraspanin and the SR-B1 scavenger receptor. J Biol Chem 278: $41624-41630$

15. Evans MJ, von Hahn T, Tscherne DM, Syder AJ, Panis M, et al. (2007) Claudin-1 is a hepatitis $\mathrm{C}$ virus co-receptor required for a late step in entry. Nature 446: 801-805. 
16. Crotta S, Stilla A, Wack A, D'Andrea A, Nuti S, et al. (2002) Inhibition of natural killer cells through engagement of CD81 by the major hepatitis $\mathrm{C}$ virus envelope protein. J Exp Med 195: 35-41.

17. Wack A, Soldaini E, Tseng C, Nuti S, Klimpel G, et al. (2001) Binding of the hepatitis $\mathrm{C}$ virus envelope protein $\mathrm{E} 2$ to $\mathrm{CD} 81$ provides a co-stimulatory signal for human T cells. Eur J Immunol 31: 166-175.

18. Kronenberger B, Herrmann E, Hofmann WP, Wedemeyer H, Sester M, et al. (2006) Dynamics of CD81 expression on lymphocyte subsets during interferonalpha-based antiviral treatment of patients with chronic hepatitis C. J Leukoc Biol 80: 298-308.

19. Zuckerman E (2003) Expansion of CD5+ B-cell overexpressing CD81 in HCV infection: towards better understanding the link between HCV infection, B-cell activation and lymphoproliferation. J Hepatol 38: 674 676.

20. Tseng CT, Klimpel GR (2002) Binding of the hepatitis C virus envelope protein E2 to CD81 inhibits natural killer cell functions. J Exp Med 195: 43-49.

21. Yoon JC, Shiina M, Ahlenstiel G, Rehermann B (2009) Natural killer cell function is intact after direct exposure to infectious hepatitis $\mathrm{C}$ virions. Hepatology 49: 12-21.

22. Conde-Vancells J, Rodriguez-Suarez E, Embade N, Gil D, Matthiesen R, et al. (2008) Characterization and comprehensive proteome profiling of exosomes secreted by hepatocytes. J Proteome Res 7: 5157-5166.

23. Fritzsching B, Schwer B, Kartenbeck J, Pedal A, Horejsi V, et al. (2002) Release and intercellular transfer of cell surface CD81 via microparticles. J Immunol 169: 5531-5537.

24. Lykke-Andersen S, Brodersen DE, Jensen TH (2009) Origins and activities of the eukaryotic exosome. J Cell Sci 122: 1487-1494.

25. Masciopinto F, Giovani C, Campagnoli S, Galli-Stampino L, Colombatto P, et al. (2004) Association of hepatitis $\mathrm{C}$ virus envelope proteins with exosomes. Eur J Immunol 34: 2834-2842.

26. Knodell RG, Ishak KG, Black WC, Chen TS, Craig R, et al. (1981) Formulation and application of a numerical scoring system for assessing histological activity in asymptomatic chronic active hepatitis. Hepatology 1: 431-435.

27. Levy S, Todd SC, Maecker HT (1998) CD81 (TAPA-1): a molecule involved in signal transduction and cell adhesion in the immune system. Annu Rev Immunol 16: 89-109.

28. Koutsoudakis G, Herrmann E, Kallis S, Bartenschlager R, Pietschmann T (2007) The level of CD81 cell surface expression is a key determinant for productive entry of hepatitis C virus into host cells. Journal of Virology 81: $588-598$.
29. Kwok S, Higuchi R (1989) Avoiding false positives with PCR. Nature 339: 237-238.

30. Thery C, Zitvogel L, Amigorena S (2002) Exosomes: composition, biogenesis and function. Nat Rev Immunol 2: 569-579.

31. Rana S, Zoller M (2011) Exosome target cell selection and the importance of exosomal tetraspanins: a hypothesis. Biochemical Society Transactions 39: 559-562.

32. Wiley RD, Gummuluru S (2006) Immature dendritic cell-derived exosomes can mediate HIV-1 trans infection. Proc Natl Acad Sci U S A 103: 738-743.

33. Whiteside TW, Mandapathil M, Szczepanski M, Szajnik M (2011) Mechanisms of tumor escape from the immune system: Adenosine-producing Treg, exosomes and tumor-associated TLRs. Bulletin du Cancer 98: E25-E31.

34. Qazi KR, Paredes PT, Dahlberg B, Grunewald J, Eklund A, et al. (2010) Proinflammatory exosomes in bronchoalveolar lavage fluid of patients with sarcoidosis. Thorax 65: 1016-1023.

35. Bacon BR (2002) Treatment of patients with hepatitis G and normal serum aminotransferase levels. Hepatology 36: S179-S184.

36. Prati D, Taioli E, Zanella A, Della Torre E, Butelli S, et al. (2002) Updated definitions of healthy ranges for serum alanine aminotransferase levels. Annals of Internal Medicine 137: 1-9.

37. Puoti C, Bellis L, Guarisco R, Dell' Unto O, Spilabotti L, et al. (2010) HCV carriers with normal alanine aminotransferase levels: Healthy persons or severely ill patients? Dealing with an everyday clinical problem. European Journal of Internal Medicine 21: 57-61.

38. Alberti A, Noventa F, Benvegnu L, Boccato S, Gatta A (2002) Prevalence of liver disease in a population of asymptomatic persons with hepatitis $\mathrm{C}$ virus infection. Annals of Internal Medicine 137: 961-964.

39. Martinot-Peignoux M, Boyer N, Cazals-Hatem D, Pham BN, Gervais A, et al (2001) Prospective study on anti-hepatitis C virus-positive patients with persistently normal serum alanine transaminase with or without detectable serum hepatitis C virus RNA. Hepatology 34: 1000-1005.

40. Zeuzem S, Diago M, Gane E, Reddy KR, Pockros P, et al. (2004) Peginterferon alfa-2a (40 kilodaltons) and ribavirin in patients with chronic hepatitis $\mathrm{C}$ and normal aminotransferase levels. Gastroenterology 127: 1724-1732.

41. Zuckerman E, Kessel A, Slobodin G, Sabo E, Yeshurun D, et al. (2003) Antiviral treatment down-regulates peripheral B-cell CD81 expression and CD5 expansion in chronic hepatitis C virus infection. J Virol 77: 10432-10436. 